\title{
ENVIRONMENTAL HEALTH RISK ASSESSMENT OF NITROGEN DIOXIDE EXPOSURE TO AMBIENT AIR POLLUTION IN KUPANG CITY
}

\author{
Suwari ${ }^{*}{ }^{\circledR}$, Herry Zadrak Kotta ${ }^{1}$, Paulus Bhuja ${ }^{1}$ \\ ${ }^{1}$ Faculty of Science and Engineering, Nusa Cendana University, Jl. Adisucipto Kampus Baru Penfui, \\ Kupang, NTT 85361 Indonesia
}

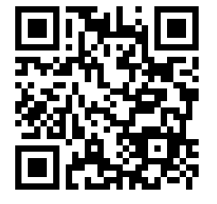

DOI: https://doi.org/10.29121/granthaalayah.v8.i6.2020.519

Article Type: Research Article

Article Citation: Suwari, Herry

Zadrak Kotta, and Paulus Bhuja. (2020). ENVIRONMENTAL HEALTH RISK ASSESSMENT OF NITROGEN DIOXIDE EXPOSURE TO AMBIENT AIR POLLUTION IN KUPANG CITY. International Journal of Research GRANTHAALAYAH, 8(6), 252-258. https://doi.org/10.29121/granthaa layah.v8.i6.2020.519

Received Date: 9 May 2020

Accepted Date: 29 June 2020

Keywords:

Environmental

Health Risk

Air Pollution

\section{ABSTRACT}

Nitrogen dioxide (NO2) is one of the main pollutants that affecting the quality of life and human health. Mostly, the effects of NO2 exposure depending on concentration, duration of exposure and anthropometric variables. This study aimed to analyzing the NO2 concentration of ambient air and to assessing human health risks in real time and lifetime exposure. To achieve that goal, air samples were taken at four strategic locations in Kupang City, in which were represented by industrial, roadside, residential, and office areas. The Griess Saltzman method was used for sampling and analysis of NO2 levels. Totally, there were 48 air samples had been analyzed for NO2 levels. The detected NO2 concentration showed a trend varied between sampling locations. Overall, NO2 levels measured still met ambient air quality standards. Human health risk assessment was carried out by determining the intake (I) and Risk Quotient (RQs) in four groups of individuals exposed to NO2. The results shown that the RQs for real time and lifetime exposures were both less than 1.0, in which implying a noncarcinogenic risk of NO2 exposure in the study area. The results Health risk assessment also indicating that potential non-carcinogenic risks occur when NO2 exposure is more than 39 years.

\section{INTRODUCTION}

Air pollution is a serious global problem because it presents a major environmental risk to health. This problem is compounded by the rapid growth of urban population, industrial development, and the increase of the transportation activities [1]. The main cause of air pollution is the burning of fossil fuels. Meanwhile, the consumption of fossil fuels continues to outweigh the use of more environmentally friendly forms of energy. This condition inadvertently has had a major effect on air quality. A study conducted by [2] indicated that transportation of motor vehicles was the main source of air pollution in urban areas. Emissions generated by motorized vehicle activities in urban areas were mainly NO2 gas originating from the combustion process [3],[4].

The impact of the use of fossil fuels clearly will reduce air quality. Furthermore, declining air quality will cause serious impacts on human health. According to [5], air pollution is an important risk factor that can cause strokes, lung cancer, heart disease and respiratory infections such as pneumonia. It was estimated that half of the deaths that occured were caused by heart disease, stroke and lung cancer which could be attributed to air pollution. The exposure to air pollution from both outdoor and household (indoor) resulted in the deaths of around 7 million people annually in all regions of the world, while Western Pacific and South East Asia were the most affected [5]. WHO

(C) 2020 The Author(s). This is an open access article distributed under the terms of the Creative Commons Attribution License, which permits unrestricted use, distribution, and reproduction in any medium, provided the original author and source are credited. 
estimated that there were 200 thousand deaths due to outdoor pollution that mainly occur in urban areas, where about $93 \%$ of cases occured in developing countries [6].

Air pollutants could come from anthropogenic activities including industry, transportation, offices and housing, but could also originated from natural activities. The transportation and industrial sectors were the highest contributors to the declining of air quality. It has been predicted that air pollution due to transportation and industrial activities will increase 10-fold in 2020 compared to the conditions in 1990 [7].

Kupang City as the capital of East Nusa Tenggara province in Indonesia, has experienced rapid development in various fields as marked by the emergence of new residentials, shopping centers, tourist centers, transportation facilities, and other various supporting infrastructure. Certainly, this condition has a negative impact on environmental quality due to an increase in air pollutants, which could have a direct impact on the deterioration of public health.

Air pollution in the city of Kupang was more dominantly influenced by anthropogenic activities that using a lot of fossil fuels. One of the common air pollutants mainly produced through combustion, including that of fossil fuels, is nitrogen dioxide (NO2). NO2 is one of a group of highly reactive gases known as oxides of nitrogen (NOx). This gas is corrosive and can irritate airways in the human respiratory system at concentrations of 1-3 ppm as well as cause lung damage if inhaled [8], [9], [10]. Studies also shown that chronic exposure to N02 possibly influencing individuals by the development of chronic diseases, including infections and obstructive pulmonary disease. Shortterm exposure to NO2 which caused minimum adverse effects for human was below $0.2 \mathrm{mg} / \mathrm{m} 3$ [11] and $0.9 \mathrm{mg} / \mathrm{m} 3$ [12]. Exposure to high levels of NO2 proven had damaging the respiratory airways. In addition, contacting with the skin or eyes can cause burns. Studies also shown that longer exposures to high concentrations of NO2 could contributed to the development of asthma and potentially increased susceptibility to respiratory infections [10], [11].

Air quality monitoring and environmental health risk assessment are very important for the purpose of air pollution control and risk management. This study aims to determine the quality of ambient air and to predict human health risks associated with NO2 exposure in Kupang City, Indonesia.

\section{MATERIALS AND METHODS}

\subsection{LOCATION AND SAMPLE COLLECTION}

The research was conducted at strategic locations in Kupang city from June to September 2019. Air sampling was taken from four different sampling points representing industrial areas, residentials, transportation (roadside), and strategic office areas in Kupang City. Air sampling followed the guidelines and methods from The Government Regulation No. 41 of 1999 [14] and Indonesian National Standards [15].

The air quality measurement equipment, in the form of an air sampler, was installed at a predetermined location with a height of $150 \mathrm{~cm}$. Basically, the procedure for air quality sampling used the wet methods. Sampling procedure used absorbent Griess Saltzman solution.

Suction of air was carried out at a flow rate, F1, of $0.4 \mathrm{~L} / \mathrm{min}$ for $1 \mathrm{~h}$ whereas temperature, air pressure and humidity were recorded. After $1 \mathrm{~h}$, the final flow rate, F2, (L/min) was recorded, then the suction pump was turned off while allowed to stand for 10 min to remove the intruder. The air samples were put into the icebox to maintain the temperature and reduced the release of gas due to rising temperature.

\subsection{CALIBRATION CURVE FOR NO2 ANALYSIS}

Respectively put in $0.0 ; 0.1 ; 0.2 ; 0.4 ; 0.6 ; 0.8$ and $1.0 \mathrm{~mL}$, of $1640 \mu \mathrm{g} / \mathrm{L}$ standard nitrite solution into a $25 \mathrm{~mL}$ erlenmeyer. Then the absorbent solution was added to the limit mark (10 ml volume), shaken and left for 15 minutes. After color formation perfectly formed, the absorbance of each standard solution was measured at the maximum wavelength. Furthermore, a calibration curve was made between the absorbance and the concentration of NO2 gas. 


\subsection{SAMPLE ANALYSIS}

Analysis of NO2 levels using the Saltzman method. The sample solution was put into a cuvette on a spectrophotometer, then measured the intensity of the pink color formed at a wavelength of $550 \mathrm{~nm}$. Read the absorbance of the test sample then calculated the concentration using a calibration curve.

\subsection{ENVIRONMENTAL HEALTH RISK ASSESSMENT}

Health risk assessment was used to predict level risk of NO2 exposure to humans. The applied method was Public Health Assessment [16].

The necessary data was collected through four stages, namely hazard identification, exposure assessment, doseresponse assessment, and risk characterization [17], [18], [19], [20].

The data was collected in order to simulate human health risks including NO2 concentration, anthropometric data and activity patterns consisting of duration exposure (tE), body weight $(\mathrm{Wb})$, inhalation rate (R), frequency of exposure (fE) and duration of exposure (Dt). For anthropometric data and activity patterns used secondary data from several references that were relevant to local conditions. Reference data used including body weight of $15 \mathrm{~kg}$ and $55 \mathrm{~kg}$, respectively representing the average weight of Indonesian children and adults [18],[21] inhalation rate of $20 \mathrm{~m} 3 /$ day or $0.83 \mathrm{~m} 3 / \mathrm{h}$ [22], tE and Dt used residential default values.

To simulate environmental health risks, four risk population groups were established, namely children $\leq 6$ years of age and housewives representing exposure of $24 \mathrm{~h} /$ day, street vendors to whom showed $12 \mathrm{~h} /$ day exposure, and employees representing $8 \mathrm{~h} /$ day exposure [18], [21].

\subsection{DATA ANALYSIS}

Analysis of NO2 concentrations in ambient air was preceded by calculation of air sample volume. Volume of taken air samples, was calculated under normal conditions $\left(25^{\circ} \mathrm{C}, 760 \mathrm{mmHg}\right)$ using the following equation:

$$
\mathrm{V}=\frac{\mathrm{F}_{1}+\mathrm{F}_{2}}{2} \times \mathrm{t} \times \frac{\mathrm{P}_{\mathrm{a}}}{\mathrm{T}_{\mathrm{a}}} \times \frac{298}{760}
$$

Where $\mathrm{V}$ is the volume of air absorbed (L); F1 and F2 are the initial and final flow rates (L/min) respectively; $\mathrm{Pa}$ is the average barometer pressure during sampling ( $\mathrm{mmHg}$ ); Ta is the average temperature during sampling (K); 298 and 760 are respectively the temperature and pressure (mmHg) under normal conditions.

Furthermore, the NO2 concentration in ambient air was calculated using the following equation:

$$
\mathrm{C}=\frac{\mathrm{a}}{\mathrm{V}} \times 1000
$$

Where $\mathrm{C}$ is NO2 concentration in the ambient air ( $\mu \mathrm{g} / \mathrm{Nm} 3)$; a is amount of NO2 from the sample by looking at the calibration curve $(\mu \mathrm{g}), \mathrm{v}$ is volume of air under normal conditions (L); and 1000 is the conversion of liter to $\mathrm{m} 3$.

Exposure assessment aimed to identify NO2 exposure pathways so that the amount of intake received by individuals in the population at risk could be calculated. Amount of NO2 intake by inhalation was calculated by the following equation:

$$
I=\frac{C \times R \times t_{E} \times f_{E} \times D_{t}}{W_{b} \times t_{\text {avg }}}
$$

Where I is inhalation intake (mg NO2/kg individual body weight /day), C is NO2 concentration in ambient air $(\mathrm{mg} / \mathrm{m} 3), \mathrm{R}$ is inhalation rate $(\mathrm{m} 3 / \mathrm{h})$, $\mathrm{tE}$ is duration exposure (h/day), $\mathrm{fE}$ is frequency exposure, 350 days/year for residential default values, Dt is duration exposure, 30 years for residential default values, Wb is individual weight (kg), tavg is average time period (Dt x 365 days/year).

Dose-response assessment was conducted for determining the relationship between level exposure of a chemical and the response in the form of events related to adverse effects or harmful effects [19]. Dose-response of 
NO2 exposure was expressed by reference concentration (RfC) as non-carcinogenic quantitative toxicity for inhalation. The RfC value for NO2 had been determined by WHO and European Environmental Agency's (EEA's) at $0.01 \mathrm{mg} / \mathrm{kg} /$ day, based on the air quality standard of NO2 for the protection of human health that is $40 \mu \mathrm{g} / \mathrm{m} 3$, exposure time $24 \mathrm{~h} /$ day, frequency of exposure 350 days/year, body weight of $70 \mathrm{~kg}$, and an average time period of 365 days/year [23], [24].

Risk characterization was expressed as non-carcinogenic risk level (Risk Quotient, RQs) due to NO2 exposure, calculated by dividing the intake (I) with RfC:

$$
\text { Risk Quotient }(R Q s)=\frac{I}{R f C}
$$

$\mathrm{RQs}<1$ presumably that daily exposure to NO2 does not have a negative effect on human health, whereas RQs $>1$ indicating a potential non-carcinogenic effect.

\section{RESULTS AND DISCUSSION}

\subsection{NO2 CONCENTRATION IN AMBIENT AIR}

NO2 measurements were carried out in the dry season, so that gas deposition due to rainwater was very minimal. Air sampling was carried out from June to September 2019. During this period precipitation occurred only twice about $8 \mathrm{~mm}$ [25]. The setting of this condition was intended to estimate the potential health of the environment that was most at risk, according to the precautionary principle. The measurement results of NO2 concentration from four strategic areas in Kupang City as presented in Table 1.

Table 1: Concentration of NO2 from ambient air in Kupang City, 2019.

\begin{tabular}{|c|c|c|c|c|c|}
\hline \multirow{2}{*}{ Location } & \multicolumn{3}{|c|}{ Concentration of $\mathrm{NO}_{2}{ }^{*}, \mu \mathrm{g} / \mathrm{m}^{3}$} & \multirow{2}{*}{ Average } \\
\cline { 2 - 5 } & June & July & August & September & \\
\hline Industrial area & 15.12 & 21.00 & 14.09 & 17.46 & 16.92 \\
\hline Roadside & 16.95 & 23.96 & 16.28 & 31.44 & 22.16 \\
\hline Residential area & 12.00 & 9.89 & 8.22 & 10.80 & 10.23 \\
\hline Office area & 5.20 & 11.23 & 12.12 & 6.19 & 8.69 \\
\hline
\end{tabular}

*Average NO2 levels from three measurements. $1 \mu \mathrm{g} / \mathrm{m} 3 \mathrm{NO} 2$ level is equal to $0.53 \mathrm{ppb}$

As Indicated in Table 1, it shown that the NO2 concentration varied between measurement times. This case could be caused by meteorological factors (such as temperature, humidity, wind, and sunlight) that occured between measurement times and/or differences in the intensity of anthropogenic activity. As primary pollutant emitted by an emission source NO2 will experience various physical and chemical reactions in the presence of meteorological factors. In this case, various reactions that occuring in the air could also cause NO2 to change into several types of secondary pollutants, for example HNO3 and dissociation of NO2 into oxygen radicals. Due to the push of the wind, NO2 gas will be dispersed (scattered) in the direction of the wind. Some NO2 on their way could be deposited on the surface of land, water, buildings, and plants. Others will remain suspended in the air. Certainly, all of these events will affect the concentration of NO2 in ambient air.

The lowest NO2 concentration was found in the office area. In this area, NO2 concentrations ranged from 5.20 to $12.12 \mu \mathrm{g} / \mathrm{m} 3$ with an average of $8.69 \mu \mathrm{g} / \mathrm{m} 3$. NO2 is an indicator for road traffic. The average of NO2 concentration at the roadside was higher than that from other three locations. The results shown that NO2 concentrations measured at Roadside ranged from 16.28 to $31.44 \mu \mathrm{g} / \mathrm{m} 3$. High NO2 concentration at that location indicated that air pollution in urban areas was mainly originated from motorized vehicles emissions. According to [26], motor vehicle exhaust gas contributed to total NO2 emissions of 185 pounds/1000 gallons. NO2 levels increased along with the increase in traffic activity. In conclusion, transportation sector, especially motor vehicles that use premium fuel contributed major source of air pullution in Kupang City [1], [4]. 


\subsection{PROJECTION OF HUMAN HEALTH RISKS}

This study simulated potential health risks to humans exposed to NO2 in ambient air by calculating the NO2 daily intake (I) and comparing it to the maximum dose allowed for humans through daily exposure. The intake calculated results was based on NO2 concentration data as a risk agent as shown in Table 2 and Table 3. Meanwhile, the characteristics of health risks due to NO2 exposure in the form of numerical values of Risk Quotient (RQs) presented in Table 4 and Table 5.

Table 2: Intake of NO2 (x 10-3 mg/kg/day) from ambient air for real time exposure

\begin{tabular}{|c|c|c|c|c|}
\hline Location & Children & Housewives & Street Vendors & Employees \\
\hline Industrial area & 3.59 & 0.98 & 0.49 & 0.33 \\
\hline Roadside & 4.70 & 1.28 & 0.64 & 0.43 \\
\hline Residential & 2.17 & 0.59 & 0.30 & 0.20 \\
\hline Office area & 1.84 & 0.50 & 0.25 & 0.17 \\
\hline
\end{tabular}

Table 3: Intake of NO2 (x 10-3 mg/kg/day) from ambient air for lifetime exposure

\begin{tabular}{|c|c|c|c|}
\hline Location & Housewives & Street Vendors & Employees \\
\hline Industrial area & 5.88 & 2.94 & 1.47 \\
\hline Roadside & 7.70 & 3.85 & 1.92 \\
\hline Residential & 3.55 & 1.78 & 0.89 \\
\hline Office area & 3.02 & 1.51 & 0.75 \\
\hline
\end{tabular}

Table 4: Risk level (RQs) of NO2 exposure at 4 locations for real time exposure

\begin{tabular}{|c|c|c|c|c|}
\hline Location & Children & Housewives & Street Vendors & Employees \\
\hline Industrial area & 0.36 & 0.10 & 0.05 & 0.03 \\
\hline Roadside & 0.47 & 0.13 & 0.06 & 0.04 \\
\hline Residential & 0.22 & 0.06 & 0.03 & 0.02 \\
\hline Office area & 0.18 & 0.05 & 0.03 & 0.02 \\
\hline
\end{tabular}

Table 5: Risk level (RQs) of NO2 exposure at 4 locations for lifetime exposure

\begin{tabular}{|c|c|c|c|}
\hline Location & Housewives & Street Vendors & Employees \\
\hline Industrial area & 0.59 & 0.29 & 0.15 \\
\hline Roadside & 0.77 & 0.38 & 0.19 \\
\hline Residential & 0.36 & 0.18 & 0.09 \\
\hline Office area & 0.30 & 0.15 & 0.08 \\
\hline
\end{tabular}

The intake values of NO2 presented in Table 2 and Table 3, mainly influenced by anthropometric variables and the actual dose of the risk agent received as well as inhalation rate by the individual. The results also strongly proved that body weight, frequency exposure, and duration exposure were the anthropometric variables that affecting pollutant intake. The greater the weight of individual, the smaller the intake received by individuals exposed to risk agents. Consequently the smaller the health risk affected by NO2 exposure in ambient air. Based on these considerations, WHO and EEA's used body weight of $70 \mathrm{~kg}$ and an inhalation rate of $20 \mathrm{~m} 3 /$ day to set NO2 quality standards, ie the annual mean value should not exceed $40 \mu \mathrm{g} / \mathrm{m} 3$ and for an average hourly maximum value of 200 $\mu \mathrm{g} / \mathrm{m} 3$ to protect human health [23], [24]. Meanwhile, air quality standards in Indonesia according to [14] for NO2 with a measurement time of 1 year and 1 hour, respectively, were $100 \mu \mathrm{g} / \mathrm{m} 3$ and $400 \mu \mathrm{g} / \mathrm{m} 3$. The setting of these air quality standards should be consider the average adult body weight and maximum duration of exposure as a substitution for the length of measurement.

In this study, the calculation of NO2 intake was applied in real time using body weight of $15 \mathrm{~kg}$ (for children) and $55 \mathrm{~kg}$ (for adults) with duration exposure of 5 years, while the intake value of NO2 for lifetime uses the duration of exposure of 30 years. Whereas other variables were fixed. The measurement results shown that the intake value of NO2 for lifetime exposure ranges from $0.17 \times 10-3$ to $4.70 \times 10-3 \mathrm{mg} / \mathrm{kg} / \mathrm{day}$. The highest NO2 intake occured in the group of children, while the lowest intake occured in the group of employees. The difference value of NO2 intake 
from four study groups was due to differences in body weight and length contact time of individuals to risk agents. The same results transformed in the value of NO2 intake for lifetime exposure, although the intake value was greater than those for real time exposure.

The highest RQs at real time exposure for 4 exposed population groups ranged from 0.04 to 0.47 (Table 4), the index had increased 0.19 to 0.77 on lifetime exposure (Table 5). The RQs (real time) and RQs (lifetime) were all less than 1.0, indicating that a long term NO2 exposure from ambient air in Kupang City did not pose a health risk and chronic toxicity for local residents, but control efforts were needed so that NO2 concentration did not increase significantly.

Estimated duration of exposure in which NO2 exposure begins to pose a health risk or chronic effect, can be done by rearranging equation (3) and substituting I (intake) with RfC. As a result, local people exposed to NO2 with concentration of $22.16 \mu \mathrm{g} / \mathrm{m} 3$ for 38.98 years had a high non-carcinogenic health risks and needed risk management. The assumption is that NO2 concentration in ambient air does not increase significantly. Additionally, increasing NO2 concentration from real time to lifetime will increase potential health risks. Scientific evidence shown that longterm exposure to high NO2 concentrations could contribute to the development of asthma and potentially increasing susceptibility to respiratory infections. Children and older adults had greater health risks [10]. NO2 could also reduce lung function. Individuals who were exposed to NO2 continuously will increase symptoms of bronchitis and emphysema, and can even worsen heart disease upto early death.

\section{CONCLUSION}

Nitrogen dioxide, NO2, concentration in four strategic locations in Kupang City, Indonesia, had not exceeded ambient air quality standards in accordance with Government Regulation No. 41 of 1999 and WHO standards. Environmental health risk analysis provided a numerical value of estimated risk due to NO2 exposure both real time and lifetime based on NO2 levels and anthropometric variables. NO2 exposure both in real time and lifetime did not pose a potential risk to human health because the RQs were all less than 1.0, but the duration of NO2 exposure to more than 39 years presumably pose a significant non-carcinogenic risk to local residents, especially individuals who live near the roadside.

\section{DATA AVAILABILITY}

Data used to support the findings of this study are included in the article.

\section{SOURCES OF FUNDING}

None.

\section{CONFLICT OF INTEREST}

The authors declare that they have no conflicts of interest regarding the publication of this article.

\section{ACKNOWLEDGMENT}

The authors would like to thank to the Research institutions and community service, Nusa Cendana University, which provided funding for this research.

\section{REFERENCES}

[1] W.A. Wardhana, Impact of Environmental Pollution, Andi Offset, Yogyakarta, 2004.

[2] Yanismai, Relationship between traffic density and air quality in the Padang City. Padang, 2004.

[3] Tania, S. and Driejena, Roadside Concentration in the City of Bandung, Faculty of Civil Engineering Environmental Engineering Study Program, Institute of Technology, Bandung, 2009. 
[4] M.G. Ghozikali, et al., "Quantification of the health effects of exposure to air pollution (NO2) in Tabriz, Iran," Fresenius Environmental Bulletin, vol. 24, no. 11c, pp. 4142-4148, 2015.

[5] WHO (World Health Organization), Ambient Air Pollution: A global assessment of exposure and burden of disease, Geneva, 2016.

[6] (World Health Organization), Fact sheet: the top 10 causes of death: the 10 leading causes of death in the world, 2000 and 2011, Geneva, 2014. [online]. www.who.int.

[7] Purwadi, J. Analysis of noise levels and emissions in slamet riyadi street and alternative solutions [Thesis]. Muhammadiyah University. Surakarta, 2006.

[8] Handayani, Effect of NO2 inhalation on lung health, mirror of the medical world No.138, Faculty of Medicine, University of Indonesia, Jakarta, 2003.

[9] E. Samoli, et al, "Short-term effects of nitrogen dioxide on mortality: an analysis within the APHEA project," European Respiratory Journal, vol. 27, pp.1129-1138, 2006.

[10] USEPA (U.S. Environmental Protection Agency), Primary national ambient air quality standards (NAAQS) for nitrogen dioxide, 2018, http:// www.epa.gov>no2-pollution.

[11] U. Latza, S. Gerdes, X. Baur, "Effects of nitrogen dioxide on human health: systematic review of experimental and epidemiological studies conducted between 2002 and 2006," International Journal of Hygiene and Environmental Health, vol. 212, no. 2, pp. 271-287, 2009.

[12] M.D.T. Lindvall, "Health effects of nitrogen dioxide and oxidant," Scandinavian Journal Works Environmental Health, vol. 11, no.3, pp. 10-28, 1985.

[13] ATSDR (Agency for Toxic Substances and Disease Registry, Nitrogen oxide (nitric oxide, nitrogen dioxide, etc), Atlanta, 2002, http://www.atsdr.cdc.gov.

[14] Government Regulation of Republic Indonesia No. 41 of 1999 concerning Air Pollution Control, Jakarta, 1999.

[15] BSN (National Standardization Agency), Ambient air-part 2: how to test nitrogen dioxide (NO2) levels by the griess satzman method using a spectrophotometer, National Standardization Agency, Jakarta, 2005.

[16] ATSDR (Agency for Toxic Substances and Disease Registry, Public Health Assessment Guidance Manual, US Department of Health and Human Services, 2005, http://www.atsdr.cdc.gov.

[17] USEPA (United State Environmental Protection Agency), Methods for Derivation of Inhalation Reference Concentrations and Application of Inhalation Dosimetry: Environmental Criteria and Assessment, Office of Health and Environmental Assessment Office of Research and Development US-EPA, 1994.

[18] A. Nukman, A. Rahman, S. Warouw, M.I. Setiadi, C.R. Akib, "Healt Risk Assessment and management of air pollution: case study in nine-heavy traffics big cities," Jurnal Ekologi kesehatan, vol. 4, no. 2, pp. 270-289, 2005.

[19] enHealth, Environmental health risk assessment: guidelines for assessing human health risks from environmental hazards, Commenwealth of Australia, Canberra, 2002.

[20] A. Rahman, Public health assessment: predictive model of environmental impact and its application for health risk management, 2007, http://www. epa.gov/iris/subs/0278.html.

[21] USEPA (United State Environmental Protection Agency), Exposure factors handbook, EPA/600/8-89-043, 1990.

[22] R.V. Kolluru, S.M. Bartell, R.M. Pitblado and R.S. Stricoff, Risk assessment and management handbook: for environmental health and safety professionals, McGraw-Hill, New York, 1996.

[23] WHO (World Health Organization), Air quality guidelines for particulate matter, ozone, nitrogen dioxide and sulfur dioxide: Summary of risk assessment, Geneva, 2006.

[24] EEA (European Environmental Agency), Nitrogen dioxide - Annual limit values for the protection of human health, 2014, http:// www.eea.europa.eu.

[25] BPS (Statistics of Kupang Municipality), Kupang municipality in figures, Kupang, 2020.

[26] H. Martono, N. Sulistiyani, "Nitrogen dioxide gas pollution in Jakarta's air at zero-point meters and 120 meters from the highway," Buletin Penelitian Kesehatan, vol. 32, no. 1, pp.35-42, 2004. 